Iranian Journal of Breast

Diseases. 2021; 13(4):67-76.
Original Article

\section{The Effect of Aerobic Training on Tumor Growth and Expression of Bcl-2 Gene and Protein in Female Mice with Breast Cancer}

\author{
Shahvali Koohshoori $\mathbf{Y}^{1}$, Marandi $\mathbf{M}^{2^{*}}$, Kargarfard $\mathbf{M}^{2}$, Vaseghi $\mathbf{G}^{3}$, \\ Moshtaghian $\mathbf{J}^{4}$ \\ ${ }^{1}$ Ph.D. Student in Exercise Physiology, Faculty of Sport Sciences, University of \\ Isfahan, Isfahan, Iran \\ ${ }^{2}$ Department of Exercise Physiology, Faculty of Sport Sciences, University of \\ Isfahan, Isfahan, Iran \\ ${ }^{3}$ Department of Applied physiology, Faculty of Medical, Isfahan University of \\ Medical Sciences, Isfahan, Iran \\ ${ }^{4}$ Department of Biology, Faculty of Sciences, University of Isfahan, Isfahan, Iran
}

Receive: 14/11/2020 Accepted: 6/2/2021

"Corresponding Author: s.m.marandi@ spr.ui.ac.ir

Ethics Approval: IR.UI.REC.1398.012

\begin{abstract}
Introduction: The aim of this study was to investigate the effect of aerobic exercise with detraining in different phases of prevention on Bcl-2 gene expression and protein.

Methods: For this purpose, 32 female BALB-c mice (18-20 g) were purchased and randomly assigned to four groups of primordial prevention (A), primary prevention (B), secondary prevention (C), and control (D). Group A performed aerobic exercise for 4 weeks, followed by injection of 4T1 cells and 8 weeks of detraining after the injection. Group B performed aerobic exercise for 4 weeks immediately after the injection of $4 \mathrm{~T} 1$ cells and then detrained for 4 weeks. Group C received a $4 \mathrm{~T} 1$ cell injection and maintained a sedentary life for 4 weeks, followed by 4 weeks of aerobic exercise. The subjects were killed 48 hours after the last training session and detraining courses and tumor tissues were removed. Real-time polymerase chain reaction was used to measure gene expression and western blotting was used to measure protein content.The one-way ANOVA test was used to analyze the data.
\end{abstract}

Results: The mean gene expression due to aerobic exercise was significantly $(\mathrm{P}<0.001)$ lower in groups A $(0.481), \mathrm{B}(0.323)$, and $\mathrm{C}(0.035)$ compared with group $\mathrm{D}$ (1.711). Also, aerobic exercise caused a significant decrease in $\mathrm{Bcl}-2(\mathrm{P}=0.005)$ protein expression in groups $\mathrm{A}(0.692), \mathrm{B}$ (0.821), and C (0.670) compared with group D (1.000). It should be noted that tumor growth in experimental groups was not significantly different from the control group $(\mathrm{P}=0.092)$.

Conclusion: Exercise may be able to reduce anti-apoptotic agents in tumor cells, leading to apoptosis of tumor cells and reduced tumor growth.

Keywords: Primordial Prevention, Primary Prevention, Secondary Prevention, Apoptosis, Aerobic Exercise, Detraining 


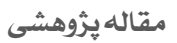

\section{تاثير دورههاى تمرين هوازى بر رشد تومور و بيان ثن و يروتئين

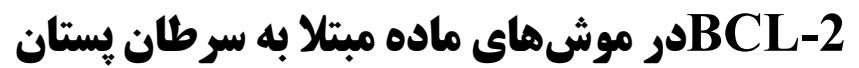

يوسف شاه ولى كوه شورى'، سيد محمد مرندى ‘ّ، مهيدى كاركرفرد'، كَلناز واثقى"، سيد جمال

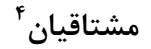

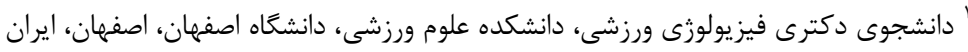

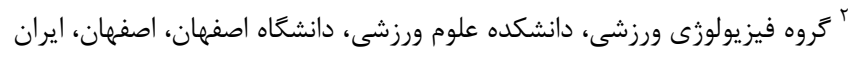

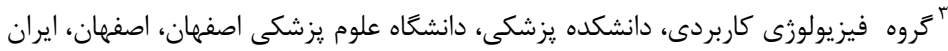

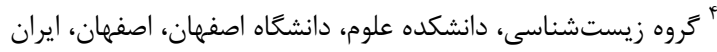

فصلنامه بيمارى هاى بستان ايران

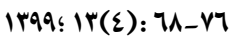

جكيده

مقدمه: هدف از تحقيق حاضر بررسى اثر تمرين هوازى به همراه بىتمرينى در فازهاى مختلف

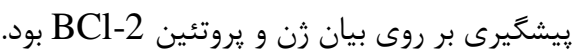
روش بررسى: r س سر موش Balb-c ماده (18-20g) خريدارى شد و بهطور تصادفى در

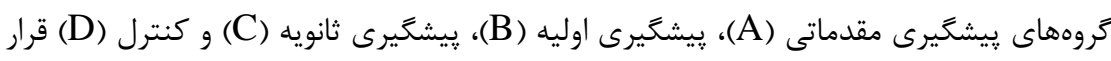

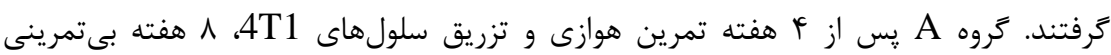

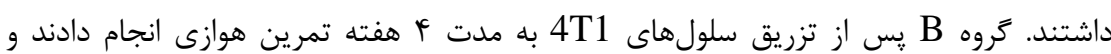

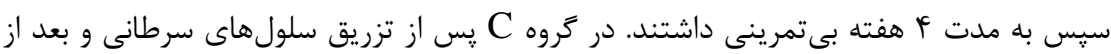

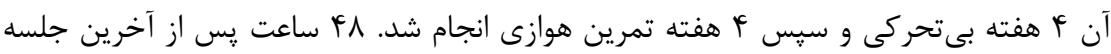

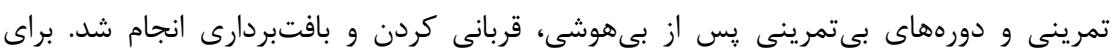
اندازه انديرى ميزان بيان زن از

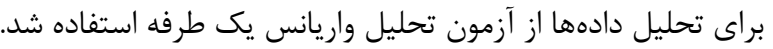

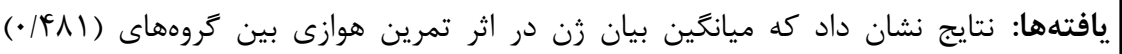

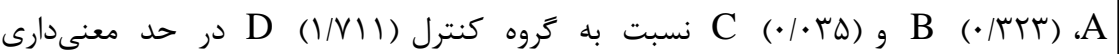

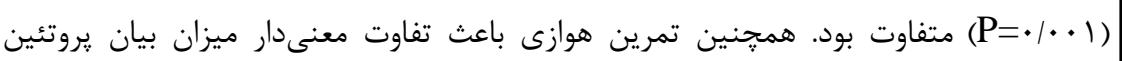
BCl-2 (P=•/.•a)

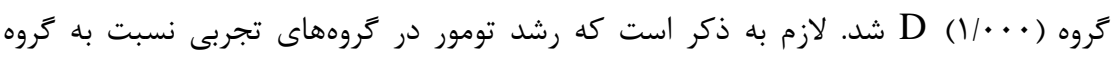

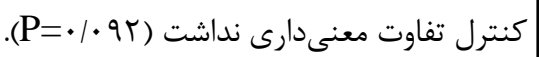

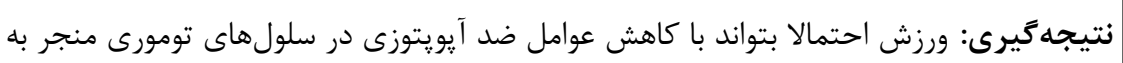

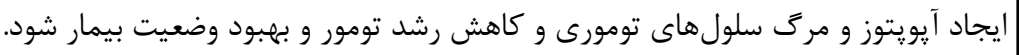

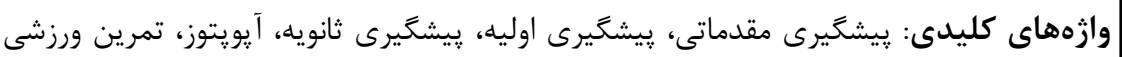

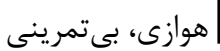

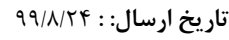

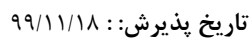

" نويسنده مسئول: s.m.marandi@spr.ui.ac.ir 
سلولهاى يوكاريوتى از مسير مهار مرك سلولى ايفا

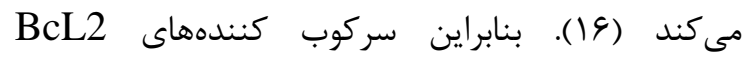

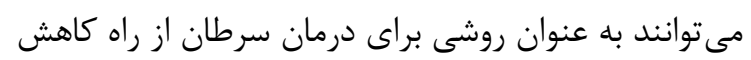

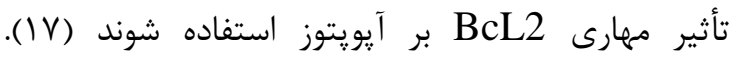

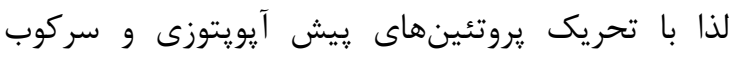

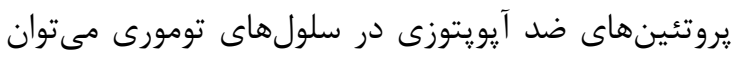
به كنترل سرطان يرداخت.

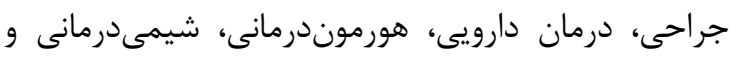

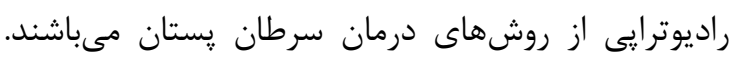

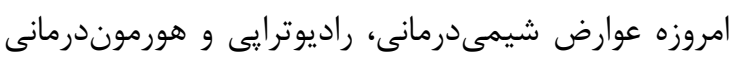
بر كسى يوشيده نيست و امكان متاستاز سلولهاى

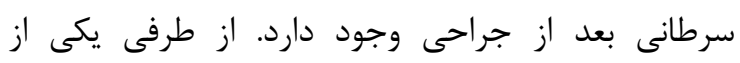

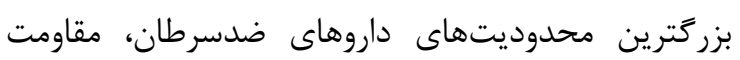

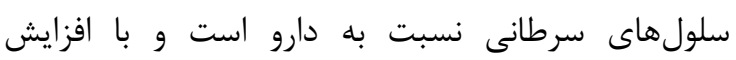

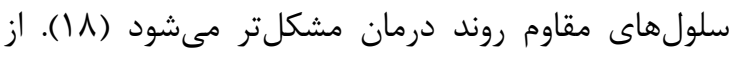

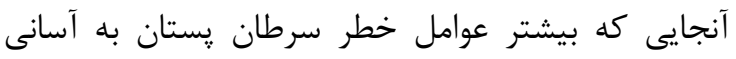

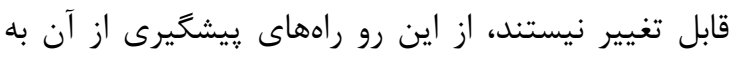

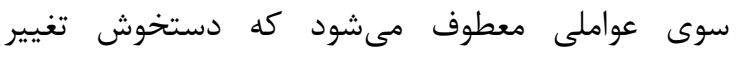

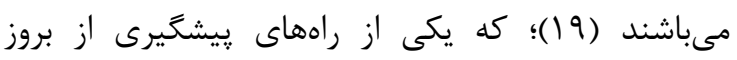

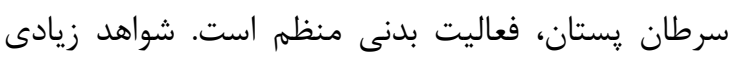

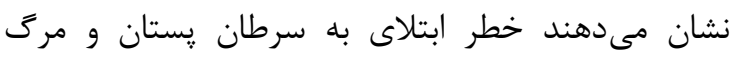

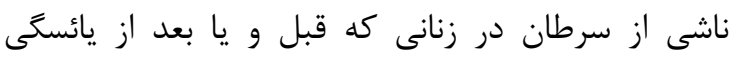

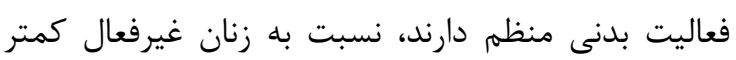

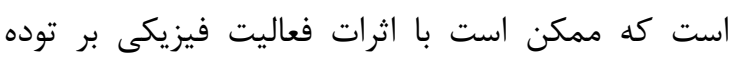

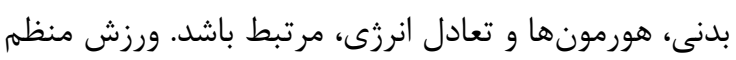

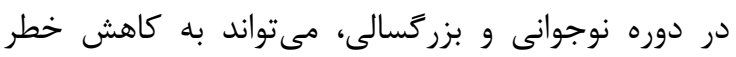

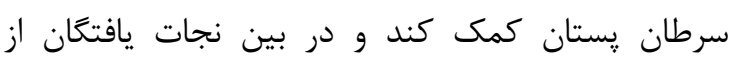

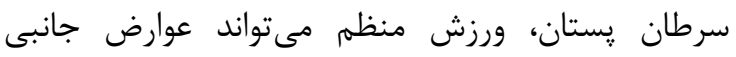

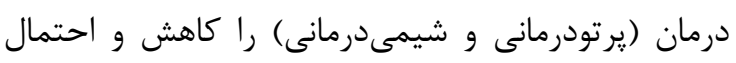

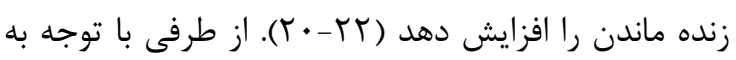

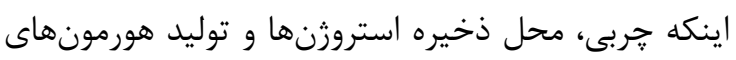

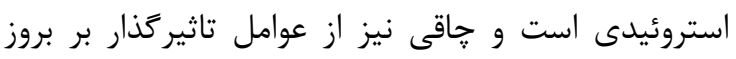
سرطانهاى مختلف است بهنظر مىرسد كه تاثير فعاليت

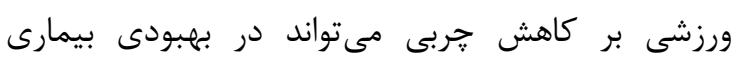

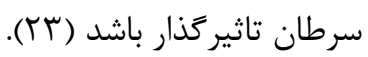
خيشگيرى مقدماتى، بهعنوان پيشخيرى از توسعه عوامل

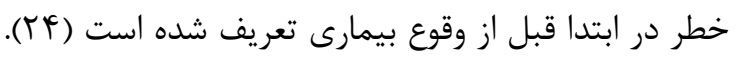
پيشگيرى اوليه عبارت است از حذف يا كاهش قرار كرفتن
مقدمه

افزايش شيوع سرطان در سالهاى اخير و تأثير آن بر ابعاد مختلف جسمى، روحى و اجتماعى زندكى انسان، آن را به آنه

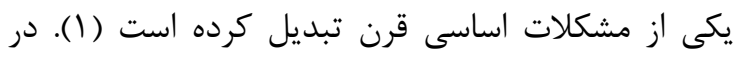

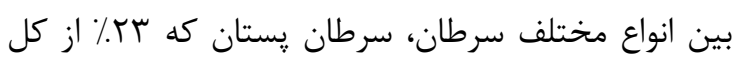

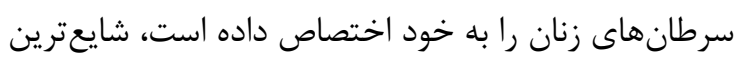

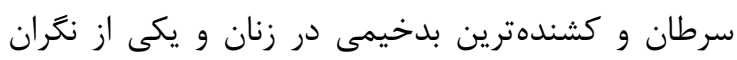

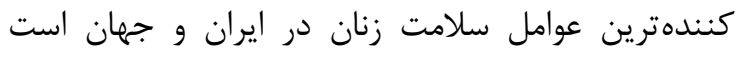
و

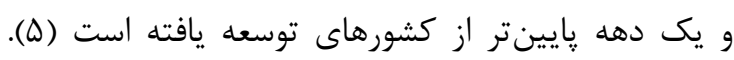

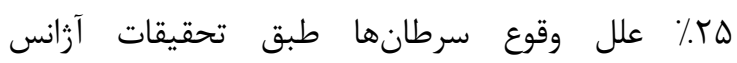

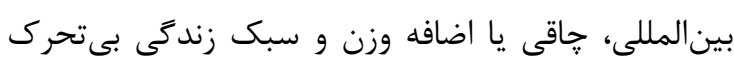

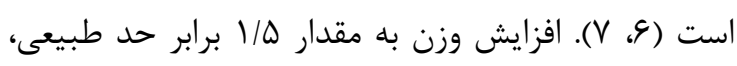

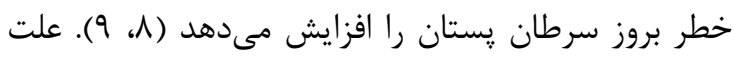

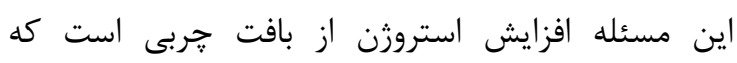

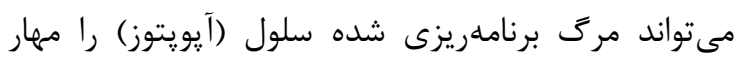

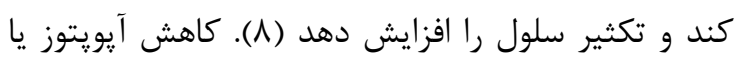

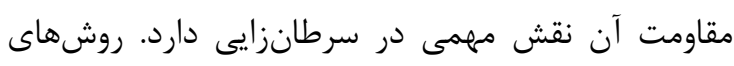

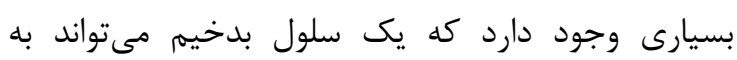
كاهش آيويتوز يا مقاومت به آيويتوز دست يابد دارد

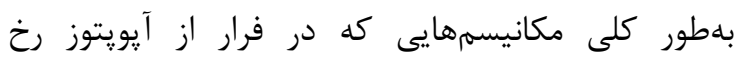

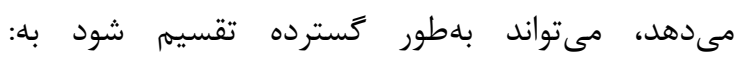

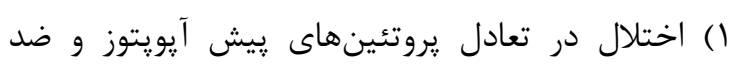

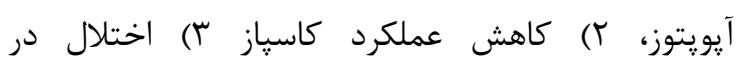

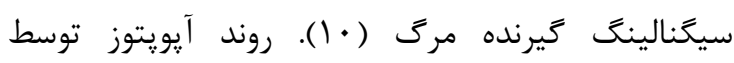

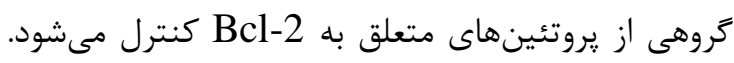

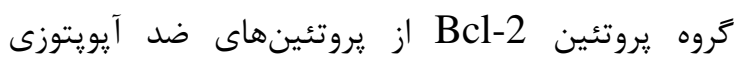

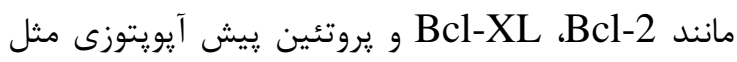
BAX

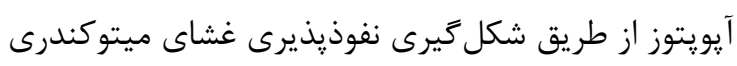

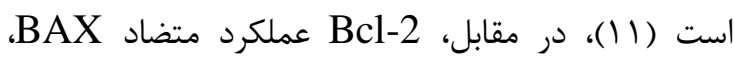

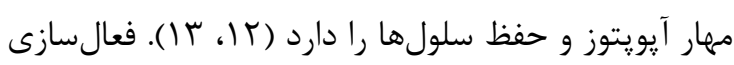

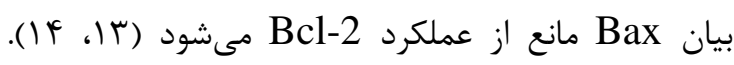

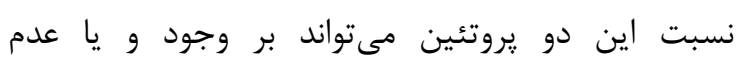

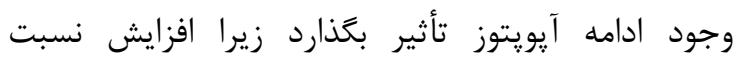
كa به به عنوان يك شاخص قابل اعتماد

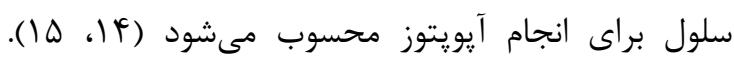
BcL2 
در كميته اخلاق دانشخاه اصفهان با شناسه IR.UI.REC.1398.012 تصويب شد.

\section{طرح تحقيق:} كشت سلولى: در اين تحقيق ابتدا رده سلولى 4T1 از

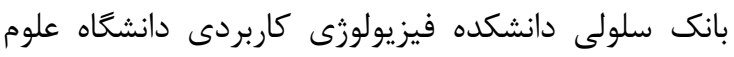

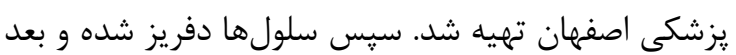
از از ساعت محيط كشت سلولها تعويض شد. سلولها در محيط 1640 RPMI با • 1. سرم جنين كاوى در

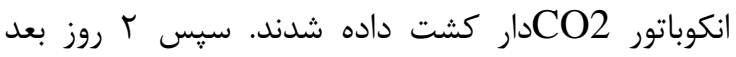
براى پاساز دادن ابتدا مايع رويى با بِييت پاستور تخليه

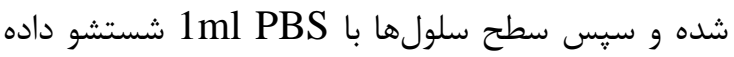

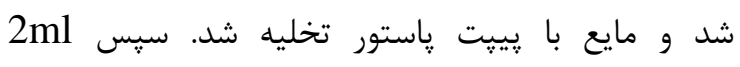

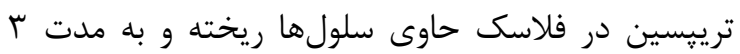

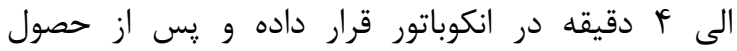

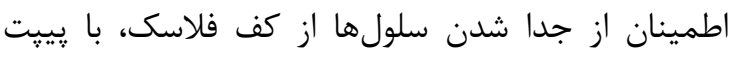

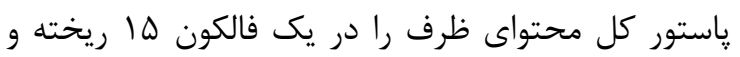
جهت خنثى كردن اثر ترييسين، محيط كشت حاوى

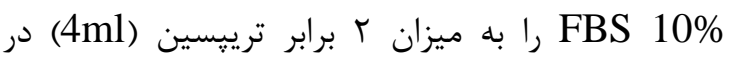

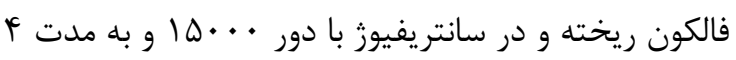
دقيقه قرار داده شد. سيس همه مايع روى پيلاك سلولى دإنى

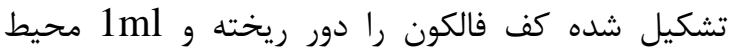

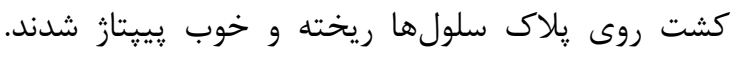
سيس شمارش سلولها روى لام در زير ميكروسكوب انجام

تزريق سلولهاى 4T1: براى ايجاد سرطان يستان، پِ

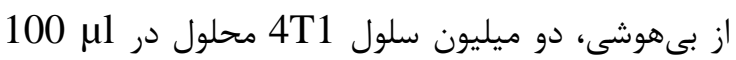
PBS100 براى هر موش به صورت زير جلدى به ناحيه

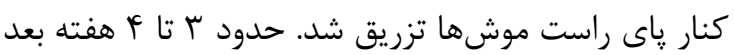
از تزريق، تومور زير يوست موشها، در ناحيه تزريق كاملا
در معرض عوامل خطر شناخته شده در جمعيتهاى

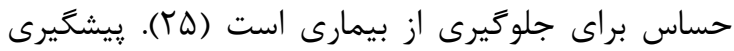

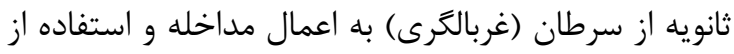
آزمايشات براى تشخيص سرطان قبل از ظهور همه علائم

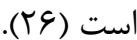

با توجه به آثار مثبت فعاليت ورزشى بر سرطان يستان، لذا مطالعه حاضر با هدف بررسى اثر تمرين هوازى در فازهاى براي

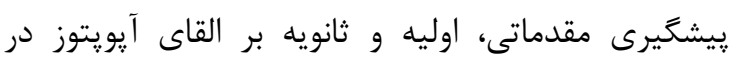
سلولهاى سرطانى موشهاى نزاد بالب سى انجام خرفته

\section{مواد و روشها}

تحقيق حاضر از نوع توسعهاى به روش تجربى با طرح يس

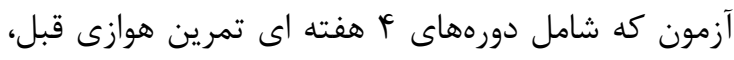
حين و بعد از ايجاد تومور بود. تعداد Tr سر موش بالب سى (هفت تا هشت هفته اى باد باد

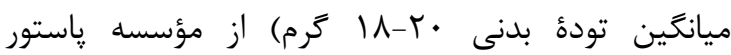

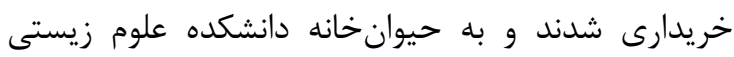
دانشكاه اصفهان منتقل كشتند. جهت تطابق فيزيولوزيك موشها، دوره Y| ساعته تاريكى - روشنايى رعايت گرديد.

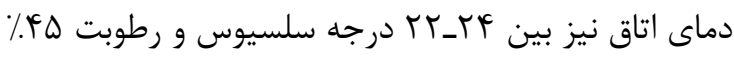
حفظ شد. قابل ذكر است كه غذاى حيوانات به صورت آزاد و دراختيار تا پايان يروتكل در دسترس موشها قرار

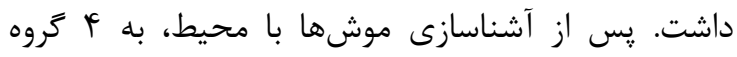

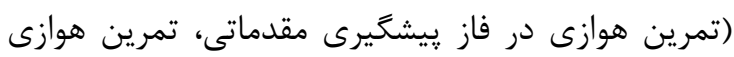
در فاز بيشگيرى اوليه، تمرين هوازى در فاز يِيشخيرى

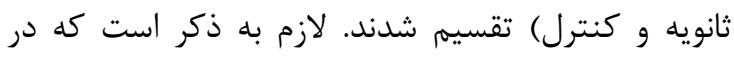

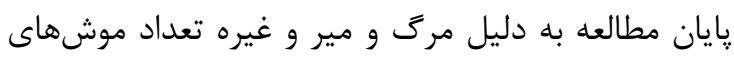
هر گروه به 9 سر كاهش يافت. ضمن اينكه طرح تحقيق ديق

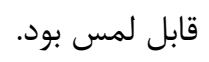

جدول ا:طرح تحقيق

\begin{tabular}{|c|c|c|c|c|c|c|}
\hline 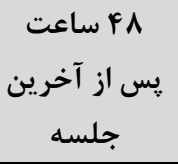 & Pفته F & F هفته F & 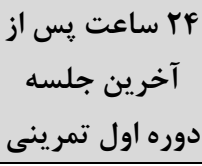 & F هفته F & r هفته & مدت زمان تروهها \\
\hline \multirow{4}{*}{ 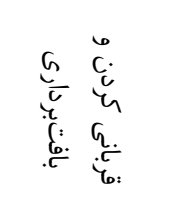 } & بى تمر ينى & بى تمرينى & \multirow{4}{*}{ 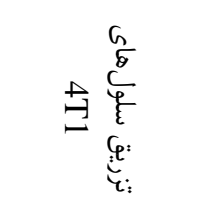 } & تمرين هوازى & \multirow{3}{*}{ 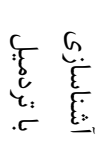 } & فاز ريشگَيرى مقدماتى \\
\hline & بى تمرينى & تمرين هوازى & & بى تحرى & & فاز بِيشگيرى اوليه \\
\hline & تمرين هوازى & بى تحرى & & بى تحر ى & & فاز ييشگيرى ثانويه \\
\hline & بىتحرى & بىتحرى & & بىتحرى & بى تحرى & كنترل \\
\hline
\end{tabular}


يروتكل وسترن بلات: براى تعيين بيان يروتئينهاى BCL-2

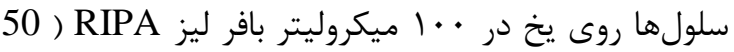
mM Tris-HCl (pH 8.0), 0.1\% sodium dodecyl sulfate, $150 \mathrm{mM}$ sodium chloride, $0.5 \%$ همخن (sodium deoxycholate, and 1.0\% NP-40 شدند و در دماى F درجه سانتى گراد به مدت لا ال دقيقه

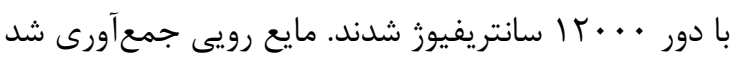
و غلظت يروتئين با استفاده از روش برادفورد با استفاده از معرفهاى تجارى Bio-Rad كمى شد ( Bio-Rad Laboratories, CA, USA الكتروفورز بر روى زل يلى آكريل آميد 12 SDS شده و سيس به غشاهاى فلورايد يلى ويلى رينيليدين از قبل فعال شده با متانول منتقل شدند. براى (PVDF)

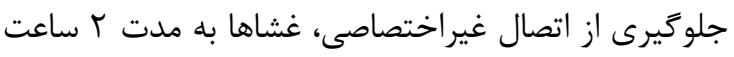

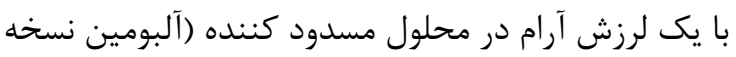

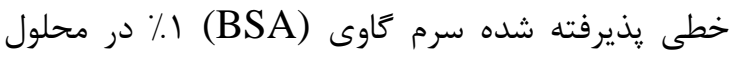

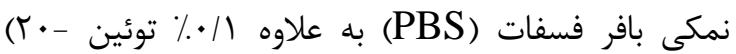

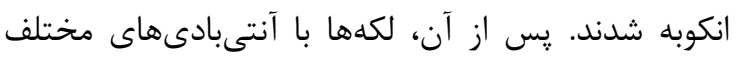

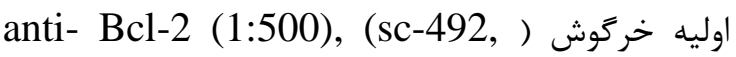
(sc-7480), and anti $\beta$-actin (1:300), (sc(47778) يك شب در دماى ₹ درجه سانتى گراد انكوبه شدند. يس از جهار بار شستشو با PBS، لكهها سرانجام

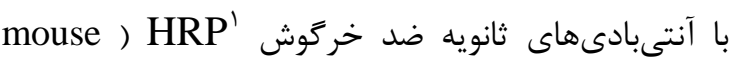
anti-rabbit IgG-HRP: sc-2357 and m-IgGк BP(HRP: sc-516102; Santa Cruz, USA (1:5000) مدت 1 ساعت در دماى اتاق انكوبه شدند. توسعه باند يروتئين با استفاده از روش شيمى لومينسانس افزايش

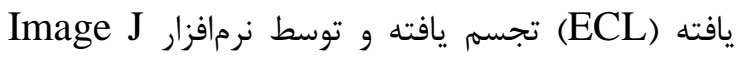
كمى شده است. در اين مطالعه از $\beta$ اكتين بهعنوان كنترل بار كذارى داخلى استفاده شد.

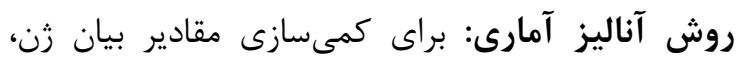
دCt GAPDH

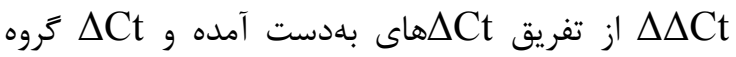

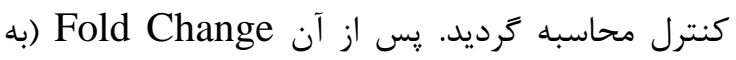

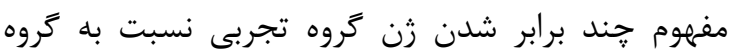
كنترل) از فرمول r به توان
يروتكل تمرين هوازى: براى اعمال مداخله تمرينى ابتدا

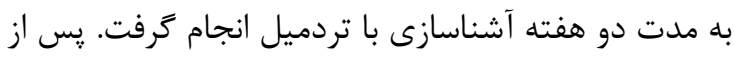

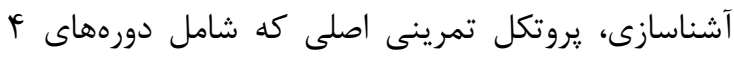

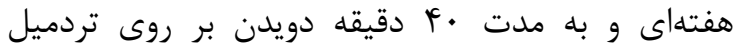

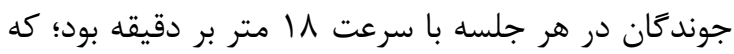
به صورت ه روز در هفته اجرا شد.

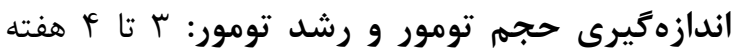

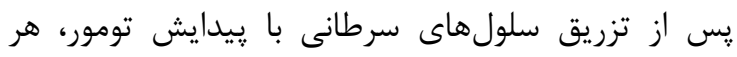

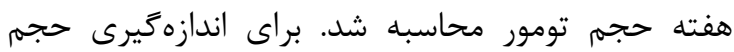
تومور از فرمول جونز و همكاران (

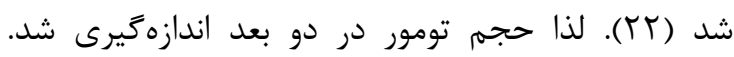

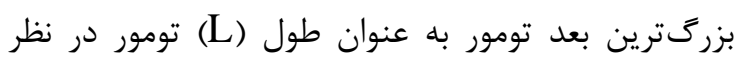

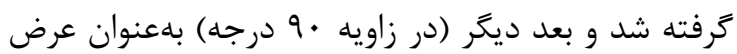

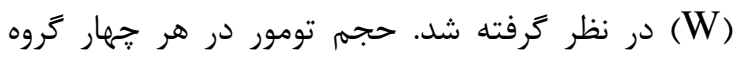

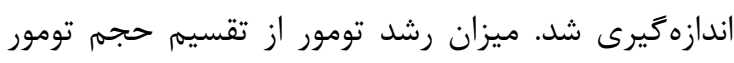

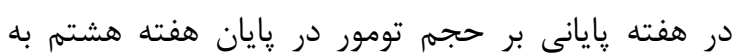

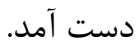
قربانى كردن موشها و بافتبردارى: ^^^ ساعت يس از

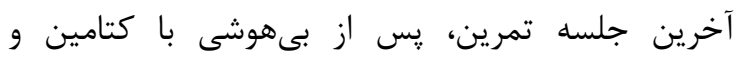

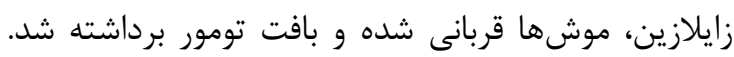

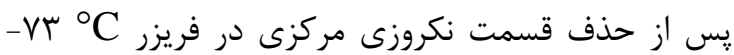

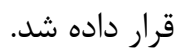
Real Time PCR Protocol

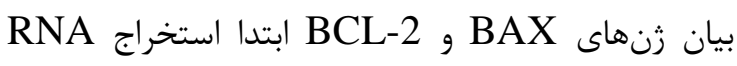
توسط محلول ROUCHE Trizol انجام شد. بعد از

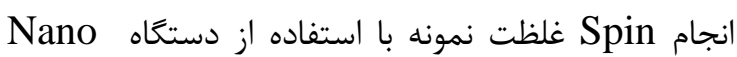
خوانده شد. براى تهيه اولين رشته از cDNA Drop

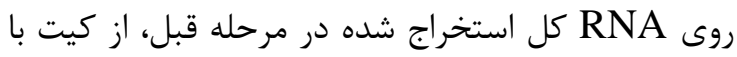

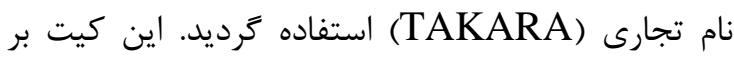
اساس آنزيم ترانس كرييتاز معكوس تهييه شده است.

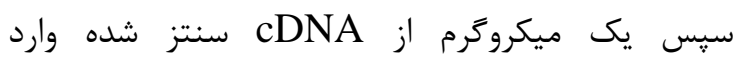
واكنشReal time PCR گرديد كه با كمك كيت سايبر كرين شركت Takara انجام كرفت. جفت بردئ يرايمرهاى مربوط به هر زن با استفاده از نرمافزار

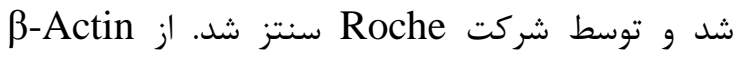

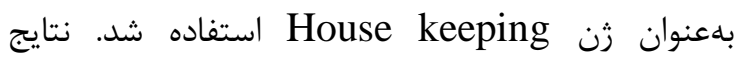
آزمايش به روش Fold change

\footnotetext{
${ }^{1}$ Horseradish Peroxidase
} 
رشد تومور، بيان زن و يروتئين BCL-2 در كروههاى

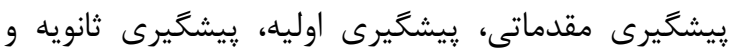

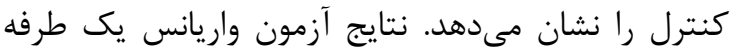

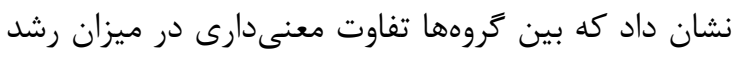
تومور وجود ندارد (F/20=2/467, P=0/092). تفاوت معنى دارى بين گروهها در ميزان بيان زن

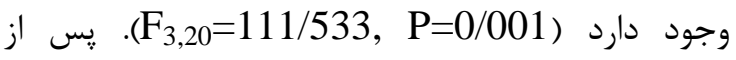
بررسى آزمون تعقيبى توكى تفاوت معنى دار بين دو كروه بيشخيرى مقدماتى و كنترل (P=0/001)، بيشكيرى اوليه و كنترل (P=0/001) و و ييشخيرى ثانويه و كنترل (P=0/001) مشاهده شد اما تفاوت بين ديخر گروهها معنى دار نبود. همجنين بر اساس آزمون تحليل واريانس

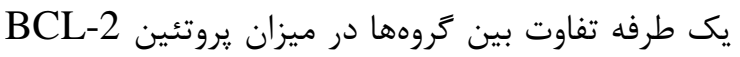

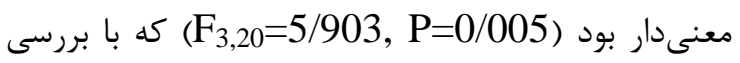

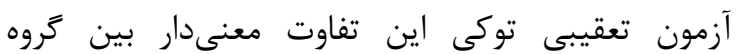

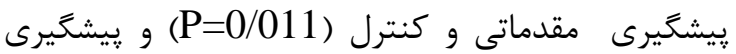
ثانويه و كنترل (P=0/007) مشاهده شد؛ اما بين ديخر كروهها تفاوت معنى دارى وجود نداشت.
از آمار توصيفى براى محاسبه ميانكين و انحراف استاندارد

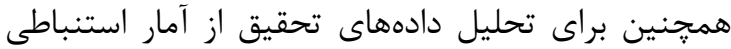

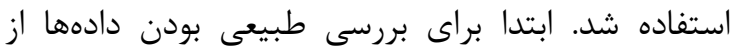

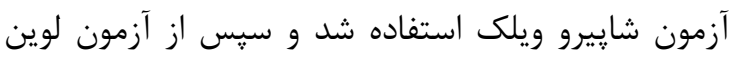
براى تعيين تجانس واريانس متغيرها استفاده شد. با توجه به وجود جهار گروه در تحقيق حاضر و مقايسه متغيرهاى تئي

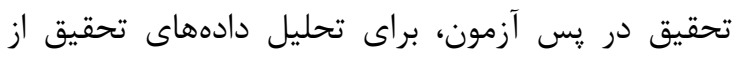
آناليز واريانس يك طرفه و آزمون تعقيبى توكى استفاده

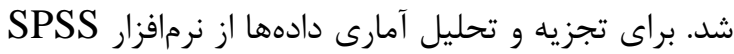

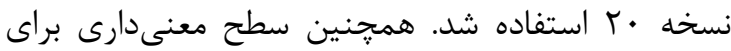
تمام آزمونها P<0/05 در نظر كرفته شد.

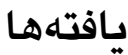

نمودار 1 ميزان افزايش حجم تومور را از پايان هفته هشتم

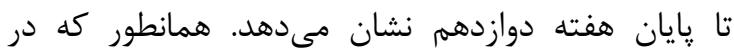
نمودار قابل مشاهده است ميزان حجم تومور در جهار كروه

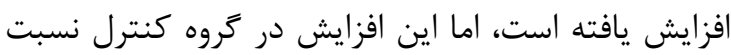
به ديخر كروهها بيشتر است. جدول شماره r ميانگين و

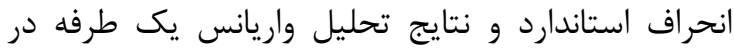

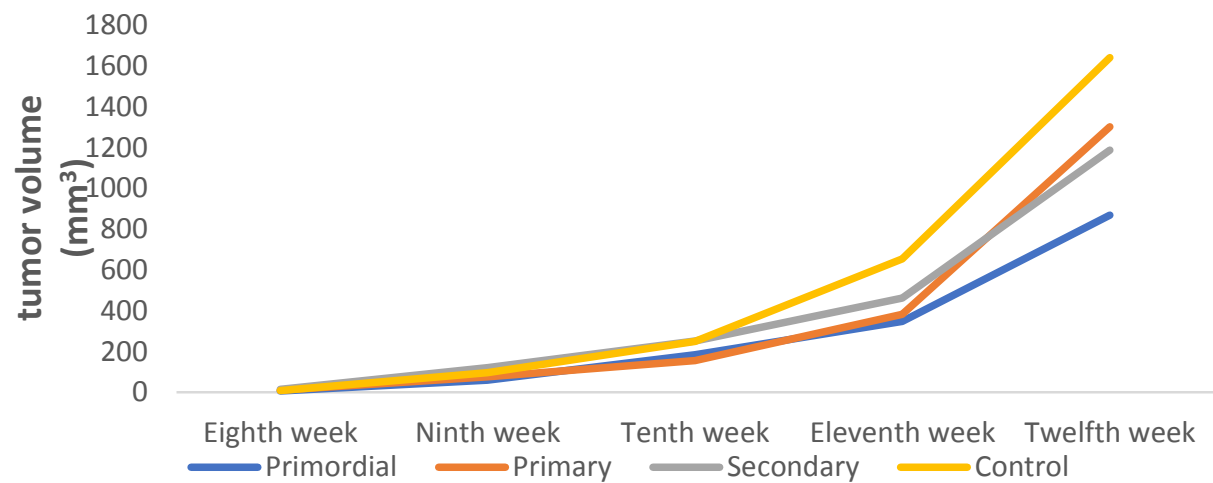

نمودار ا: ميزان حجم تومور موشها از يايان هفته هشتم تا يايان هفته دوازدهم مطالعه

جدول r: نتايج تحليل واريانس يك راهd متغيرهاى تحقيق در F كروه

\begin{tabular}{|c|c|c|c|c|c|c|c|}
\hline $\mathbf{P}$ & $\mathbf{F}$ & كنترل & ثِيشعيرى & بيشخيرى & مقيشعَيرى & & متغيرهاى تحقيق \\
\hline \multirow{2}{*}{.1 .94} & \multirow{2}{*}{ T/AGV } & rब१/V९V & IVT/VDS & $T \cdot T / T \cdot V$ & $194 / 9 r$. & ميانگين & \multirow{2}{*}{ رشد تومور } \\
\hline & & $9 \cdot 1 \cdot 1$. & $q q / 4 \ldots$ & $f \mid / \cdots 1$ & $r \Delta / \cdot r$. & انحراف استاندارد & \\
\hline \multirow{2}{*}{$\cdot 1 \cdot .1$} & \multirow{2}{*}{ سM/DH } & $1 / V 1 \cdot V$ & . /.rAT & - ITTYA & $. / 4 N \mid t$ & ميانغين & \multirow{2}{*}{$\begin{array}{r}\text { بيان زن } \\
\text { BCL-2 }\end{array}$} \\
\hline & & $\cdot / r \Delta \Lambda$. & $. / \cdot \mid \lambda F$ &.$/ 149 \mathrm{~V}$ & - /IDTF & انحراف استاندارد & \\
\hline \multirow{2}{*}{$\cdot / \cdot \Delta$} & \multirow{2}{*}{$\Delta / q \cdot r$} & $1 / \cdots$ & $.1999 \mathrm{~V}$ & - $/ A Y I Q$ & .19919 & ميانغين & \multirow{2}{*}{$\begin{array}{r}\text { BCL-2 protein } \\
\text { fold of control }\end{array}$} \\
\hline & & $\cdot 1 \cdot \cdots$ & $\cdot / / \Delta \Delta \varphi$ & $\cdot|1 \wedge|$ & .11914 & انحراف استاندارد & \\
\hline
\end{tabular}




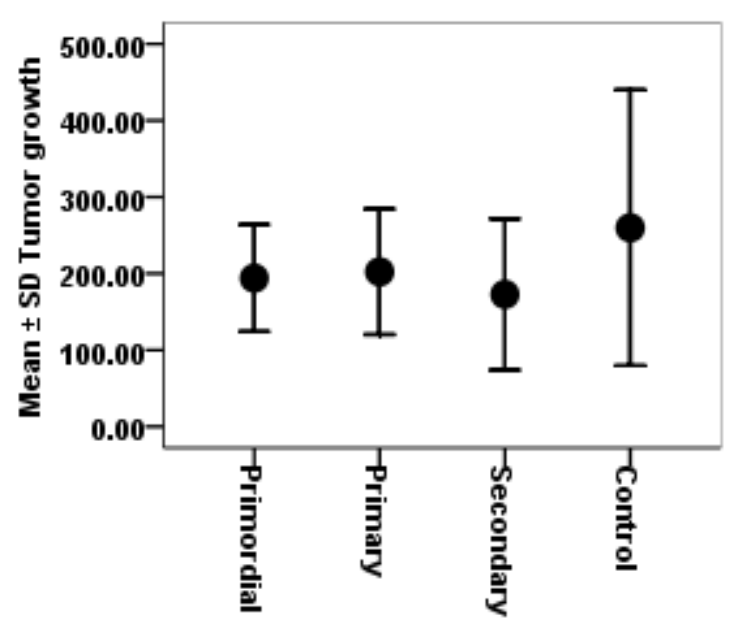

نمودار r: ميانكين و انحراف استاندارد ميزان رشد تومور در گروههاى مطالعه

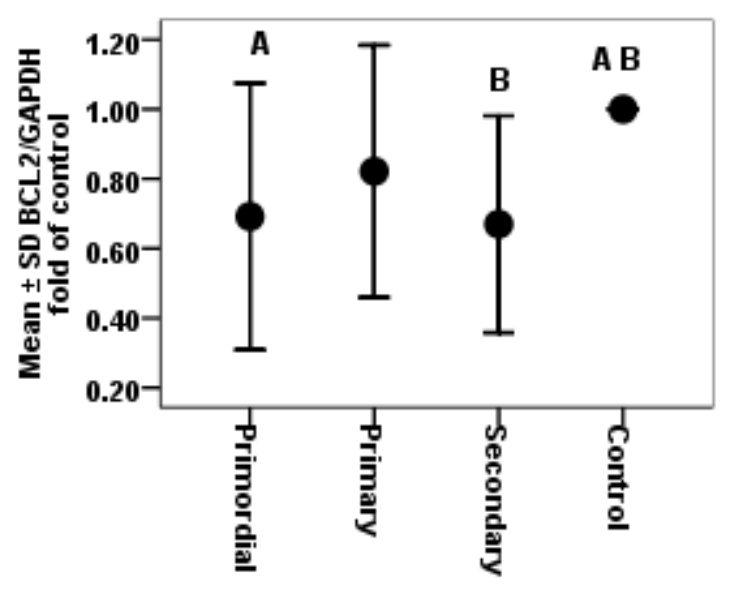

A تفاوت معنى دار فاز مقدماتى و كنترل (يروتئين) : B

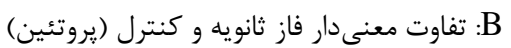

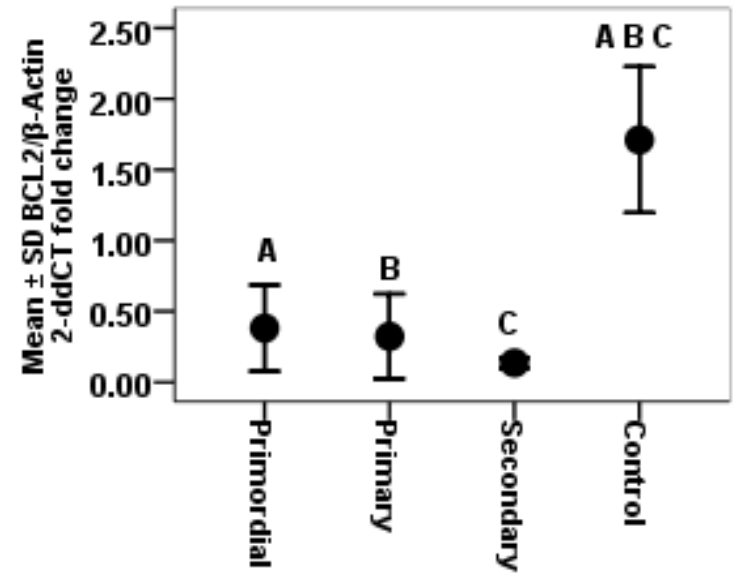

A تفاوت معنى دار فاز مقدماتى و كنترل (بيان زن) : ت

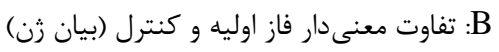

C

نمودار سז: ميانغَين و انحراف استاندارد بيان زن و يروتئين BCL-2 در تروههاى مطالعه

و عليزاده و همكاران (·r) همسو بود. ززارش شده است

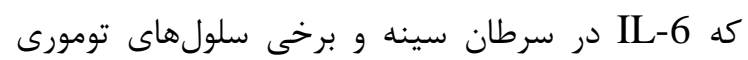

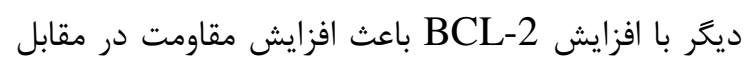

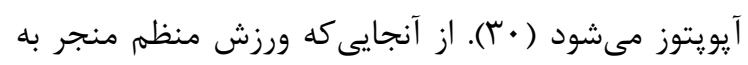

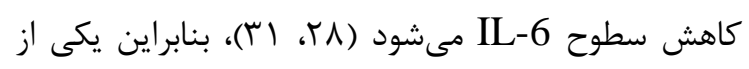

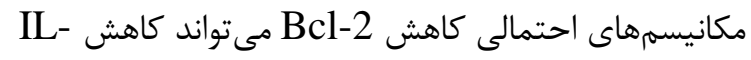
6 باشد. از طرفى BCL-2 با جلو از سيتوزول به ميتوكندرى ميىتواند منجر به كاهش BAX

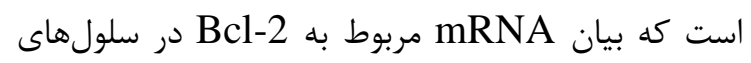
تحت درمان با antimiR-21 كاهش يافته است. -miR

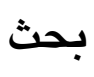

اين يزوهش با هدف بررسى اثر جهار هفته تمرين هوازى در فازهاى مختلف بر بيان زن و يروتئين BCL-2 تومور انجام شد. نتايج مطالعه حاضر نشان داد كه تمرين

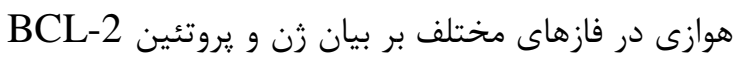

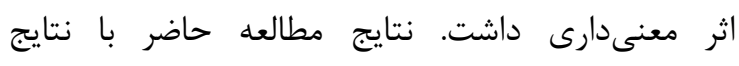
De lima

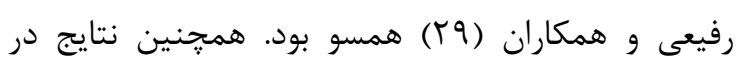
مورد بيان زن و يروتئين BAX تاثير معنى هودار تمرين هوازى در فازهاى مختلف را نشان داد. اين نتايج با نتايج

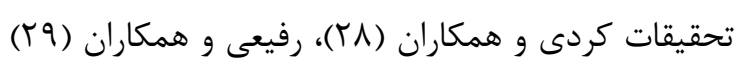


نشان نداد. دوره تمرينى كوتاه مدت مىتواند يكى از دلايل احتمالى عدم كاهش رشد تومور در تحقيق حاضر باشد. از

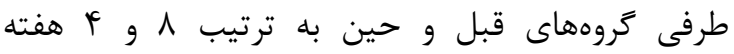
detraining داشتند. Detraining بر خلاف تمرين منظم باعث افزايش رشد تومور مىشود (•)(ا). بهنظر مىرسد طول

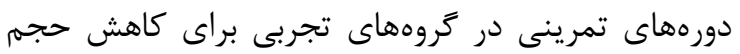

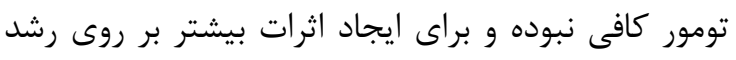
تومور بايد دورههاى تمرينى طولانىتر مورد بررسى قرار

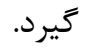
در اين مطالعه تاثير دورههاى تمرينى جهار هفتهاى بر روى رشد تومور و بيان زن و يروتئين BCL-2 مورد

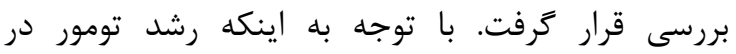

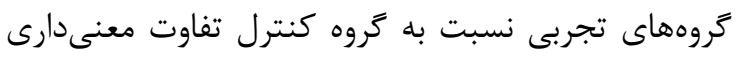

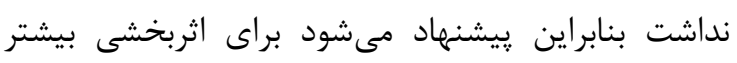

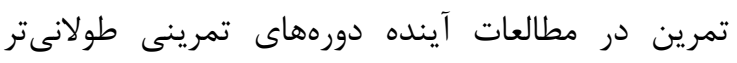
بررسى شود و همجنين دورههاى مختلف تمرينى با همر

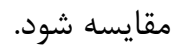

\section{نتيجهكيرى}

ورزش هوازى از طريق مكانيسمهاى مختلف، رشد سلولهاى تومور را كاهش مى دهد، يكى از آنها ايجاد

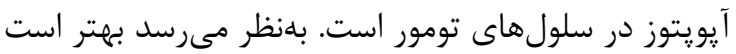

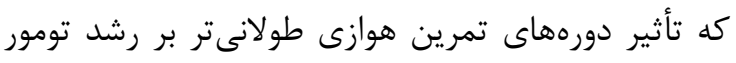

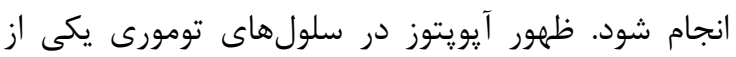
اولين يديدههايى است كه مىتواند رشد تومور را كنترل

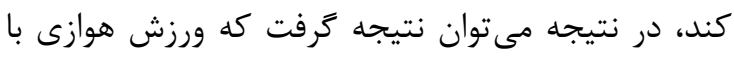
افزايش آيويتوز در سلولهاى سرطانى ندي ممكن است سلامت

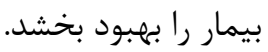

\section{تشكر و قدردانى}

نويسندًان از سركار خانم دكتر دانا به خاطر آموزش صبورانه و كمكهاى ايشان در راستاى اجراى هرجه بهر بهتر اين تحقيق كمال تشكر و قدردانى را دارند.

\section{تعارض منافع}

نويسندكان اعلام مىدارند كه هيجگَّنه تعارض منافعى در يزوهش حاضر وجود ندارد.
21 ممكن است به طور غيرمستقيم بيان Bcl-2 را تنظيم كند (سب). بر اين اساس، يك توضيح احتمالى مى تواند

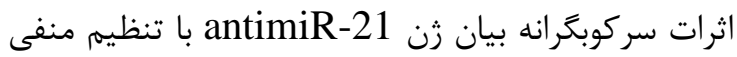

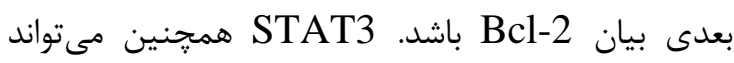

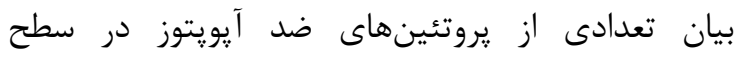

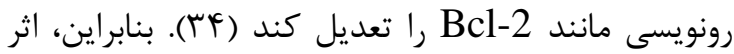

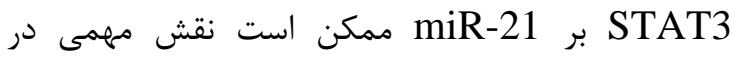
كنترل بيان Bcl-2 داشته باشد. در مطالعه حاضر، تمرين ورزشى يروتئين Bax را در بافتهاى تومور موشها داديا

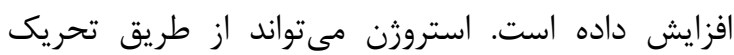
Bcl-2 وجود دارد كه فعاليت بدنى باعث تعديل سرطانزايى ناشى إنى از استروزن در سرطان يستان از طريق جندين مكانيسم

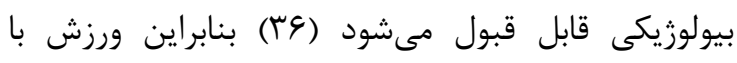
كاهش سطوح استروزن مىتواند منجر به افزايش آيويتوز از طريق كاهش BCL-2 شود. تفاوت بين گروه پِيشخَيرى

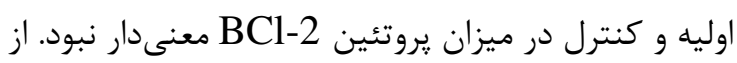

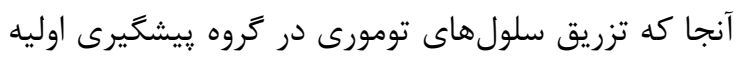
همزمان با تمرين ورزشى صورت كرفت، ممكن است اثرات

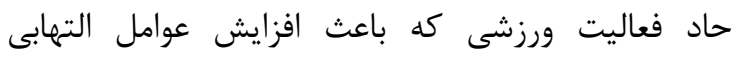
مىشود منجر به عدم معنى دارى در كاهش ميزان يروتئين

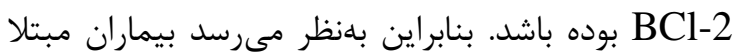

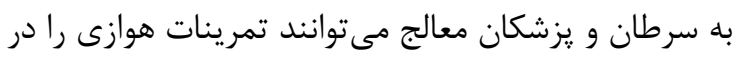

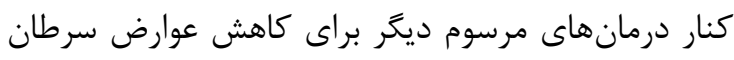

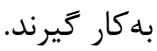
نتايج يزوهش حاضر نشان داد كه تفاوت معنىدارى بين

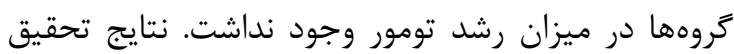

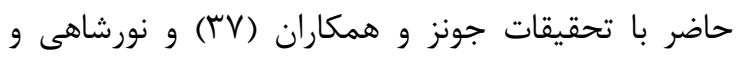

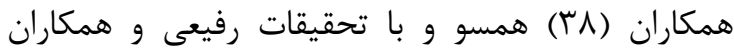

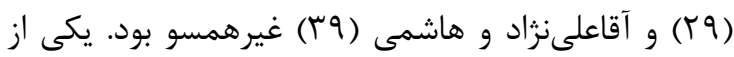
دلايل احتمالى اختلاف نتايج تحقيق حاضر با تحقيق

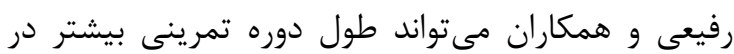
مطالعه مذكور باشد. همجنين در تحقيق رفيعى و همكاران

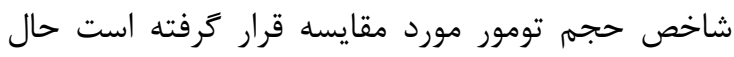

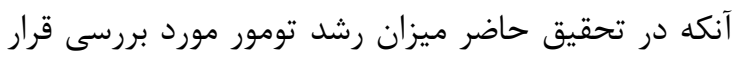

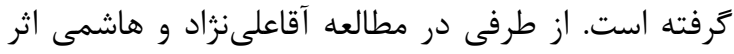
تمرين هوازى به همراه نانو ذرات سلنيوم بر روى درى حجم

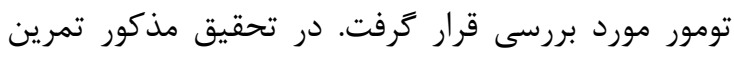

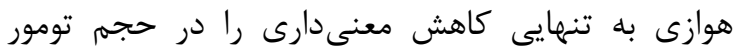




\section{References}

1. Poorkiani M, Hazrati M, Abbaszadeh A, Jafari P, Sadeghi M, Dejbakhsh T, et al. Does arehabilitation program improve quality of life in breast cancer patients. Payesh. 2010; 9(1):61-8.

2. Nafissi N, Saghafinia M, Motamedi MH, Akbari ME. A survey of breast cancer knowledge and attitude in Iranian women. J Cancer Res Ther. 2012; 8(1): 46-9.

3. Banegas MP, Bird Y, Moraros J, King S, Prapsiri S, Thompson B. Breast cancer knowledge, attitudes, and early detection practices in United States-Mexico border Latinas. J Womens Health (Larchmt). 2012; 21(1): 101-7.

4. Harirchi I, Kolahdoozan S, Karbakhsh M, Chegini N, Mohseni SM, Montazeri A, et al. Twenty years of breast cancer in Iran: downstaging without a formal screening program. Ann Oncol.2011; 22(1):93-7.

5. Xue F, Michels KB. Diabetes, metabolic syndrome, and breast cancer: a review of the current evidence. J Clin Nutr. 2007; 86: 82335.

6. Hoffman LG, Wahnefried WD, Goran MI, McTiernan A, Reichman ME. Possible mechanism mediating an association between physical activity and breast cancer. Cancer Supplement. 1998;83(3):621-28.

7. Nieman DC, Nehlsen-Cannarella SI, Henson DA, Butterworth DE, Fagoaga OR, Warren $\mathrm{BJ}$, et al. Immune response to obesity and moderate weight loss. Int. J. Obes. 1996; 20: 353-60.

8. SY Wong. Apoptosis in cancer: from pathogenesis to treatment Rebecca. Wong Journal of Experimental \& Clinical Cancer Research. 2011; 30: 87.

9. Kroemer G, Galluzzi L, Brenner C. Mitochondrial membrane permeabilization in cell death. Physiol. Rev. 2007; 87(1): 99-163.

10. Campbell K, Tiernan A, Li SS, Sorensen BE, Yasui Y, Lampe JW, et al. Effect of a 12month exercise intervention on the apoptotic regulating proteins bax and $\mathrm{Bcl}-2$ in colon crypts: A randomized controlled trial. Cancer Epidemiol. Biomarkers Prev. 2007;16(9): 1767-74.

11. Foo JB, Yazan LS, Tor YS, Wibowo A, Ismail $\mathrm{N}$, How $\mathrm{CW}$, et al. Induction of cell cycle arrest and apoptosis by betulinic acid-rich fraction from Dillenia suffruticosa root in MCF-7 cells involved p53/p21 and mitochondrial signalling pathway. J Ethnopharmacol. 2015;166: 270-8.
12. Aruoma OI, Bahorun T, Agnihotri AK. Cancer risks and perspectives: Molecular mechanisms. Mutat. Res. 2014; 768: 1-5.

13. McIlwain DR, Berger T, Mak TW. Caspase functions in cell death and disease. Cold Spring Harb Perspect Biol. 2013;5(4): a008656.

14. Cory S, Adams J M. The BcL2 family: Regulators of the cellular life-or-death switch. Nature Reviews Cancer. 2002; 2(9): 647-56.

15. Kim R, Emi M, Tanabe K, Toge T. Therapeutic potential of antisense Bcl- 2 as a chemosensitizer for cancer therapy. Cancer. 2004; 101(11): 2491-502.

16. Friedenreich CM, Cust AE. Physical activity and breast cancer risk: impact of timing, type and dose of activity and population subgroup effects. Br J Sports Med. 2008; 42(8): 636-47.

17. Eliassen AH, Hankinson SE, Rosner B, Holmes MD, Willett WC. Physical activity and risk of breast cancer among postmenopausal women. Arch Intern Med. 2010; 170(19): 1758-64.

18. Siegel RL, Miller KD \& Jemal A. Cancer statistics. CA: A Cancer Journal for Clinicians 2018; 68(1): 7-30.

19. Lahmann PH, Hoffmann K, Allen N, Van Gils $\mathrm{CH}$, Khaw KT, Tehard B, et 1 . Body size and breast cancer risk: findings from the European Prospective Investigation into Cancer And Nutrition (EPIC). International Journal of Cancer. 2004; 111(5): 762-71.

20. Moodi M, Sharifirad GR, Tahergorabi Z, Mostafavi F. [Get to Know Breast Cancer Pathway toward Health. 1 Th ed]. Isfahan University of Medical Sciences Publisher. Isfahan 2012.

21. O'Connell S, Asnltzr B, Sami P. Disease in women and breast and genitals- urinary male. Tehran: Tohfeh. 2004; 144

22. Jones LW, Viglianti BL, Tashjian JA, Kothadia SM, Keir ST, Freedland SJ, et al. Effect of aerobic exercise on tumor physiology in an animal model of human breast cancer. Journal of Applied Physiology. 2010; 108(2):343-8

23. Lima C, Alves L, Fabíola, J, Machado A, Kryczyk M, Yamazaki R, et al. Tumor growth reduction in Walker 256 tumor-bearing rats performing anaerobic exercise: participation of Bcl-2, Bax, apoptosis, and peroxidation. Appl. Physiol. Nutr. Metab. 2011;36(4):533-8. 
24. Strasser T. Reflections on cardiovascular diseases. Interdiscip Science Rev. 1978; 3: 225-30.

25. Danaei G, et al. Causes of cancer in the world: comparative risk assessment of nine behavioural and environmental risk factors. Lancet. 2005; 366(9499):1784-93.

26. Eddy DM. Secondary prevention of cancer: an overview. Bulletin of the World Health Organization. 1986; 64(3): 421-9

27. Almassi Nokiani F, Akbari H, Madani H, Izadi B. Prevalence of Breast Cancer in Breast Sample Reports in Iran, 2001-2004. The Breast Journal 2007; 13(5): 536.

28. Khori V, Amani Shalamzari S, Isanejad A, Alizadeh AM, Alizadeh S, Khodayari S, Khodayari H, Shahbazi Sh, Zahedi A, Sohanaki H, Khaniki M, Mahdian R, Saffari M, Fayad R. Effects of exercise training together with tamoxifen in reducing mammary tumor burden in mice: Possible underlying pathway of miR-21. European Journal of Pharmacology. 2015; 765:179-87.

29. Rafiei M, Gaeini A, Kordi MR, Nuri R. The Effect of Eight Weeks of Aerobic Exercise on Gene Expression of Cytochrome C, Caspase 9 and Tumor Volume in Mice with Breast Cancer. Report of Health Care. 2018; 4(4): 5560

30. Alizadeh AM, Heydari Z, Rahimi M, Bazgir B, Shirvani H, Alipour S, Heidarian Y, Khalighfard S, Isanejad A. Oxytocin mediates the beneficial effects of the exercise training on breast cancer. 2017;103(2):222-35.

31. I Garcia-Tun o'n, M Ricote, A Ruiz, B Fraile, R Paniagua \& M Royue. IL-6, its receptors and its relationship with bcl-2 and bax proteins in infiltrating and in situ human breast carcinoma. Histopathology 2005; 47: 82-9.

32. Amani Shalamzari S, Agha-Alinejad H, Alizadeh Sh, Shahbazi Sh, Kashani Khatib Z, Kazemi A, Saei MA, Minayi N. The effect of exercise training on the level of tissue IL-6 and vascular endothelial growth factor in breast cancer bearing mice. Iran J Basic Med Sci. 2014;17(4):231-58.
33. Murphy KM, Ranganathan V, Farnsworth ML, Kavallaris M, Lock RB. Bcl-2 inhibits Bax translocation from cytosol to mitochondria during drug-induced apoptosis of human tumor cells. Cell Death and Differentiation. 2000; 7: 102-11.

34. Yan LX, Wu QN, Zhang Y, Li YY, Liao DZ, Hou JH, et al. Knockdown of miR-21 in human breast cancer cell lines inhibits proliferation, in vitro migration and in vivo tumor growth. Breast Cancer Res. 2011; 13(1):1-14

35. Isomoto $\mathrm{H}$, Kobayashi $\mathrm{S}$, Wemeburg NW, Bronk SF, Guicciardi ME, Frank DA, Gores G. Interleukin 6 upregulates myeloid cell leukemia-1 expression through a STAT3 pathway in cholangiocarcinoma cells. Hepatology. 2005; 42(6):1329-38.

36. Wang GL, Jiang BH, Rue EA, Semenza GL. Hypoxia-inducible factor 1 is a basic-helixloop-helix-PAS heterodimer regulated by cellular O2 tension. Proc Natl Acad Sci USA. 1995; 92(12):5510-14.

37. Yvonne M. Coyle. Physical activity as a negative modulator of estrogen-induced breast cancer. Cancer Causes Control 2008; 19:10219.

38. W Jones L, L Viglianti B, A Tashjian J, M Kothadia S, T Keir S, J Freedland S, Q Potter M, Moon E, Schroeder T, E. Herndon J, and W. Dewhirst M. Effect of aerobic exercise on tumor physiology in an animal model of human breast cancer. J Appl Physiol. 2010; 108(2): 343-8.

39. Agha-Alinejad H, Hashemi Jokar E. Effect of Six Weeks of Interval Exercise Training along with Selenium Nanoparticle Ingestion on Bcl2 and LC3 Genes expression in the Tumor Tissue of Breast Tumor-Bearing Mice. Iranian Quarterly Journal of Breast Disease. 2019; 12(2): 26-37.

40. Zhanyang Fei, Dengke Li, Kaiming Li, Ming Zhou, Yong Li, Yiqun Li, Zhenxiao Sun. Detraining after tumor-bearing accelerates tumor growth while continuous training decreases tumor growth in mice. Journal of Traditional Chinese Medical Sciences. 2020; 7(1):75-81. 